\title{
Long-term effect of vasodilator therapy in pulmonary hypertension due to COPD: A retrospective analysis
}

Fossati, Laura ; Müller-Mottet, Séverine ; Hasler, Elisabeth ; Speich, Rudolf ; Bloch, Konrad E ; Huber, Lars C ; Ulrich Somaini, Silvia

\begin{abstract}
PURPOSE: Pulmonary hypertension $(\mathrm{PH})$ due to COPD has dismal prognosis. We reviewed the long-term effect of PH-target therapy in severe PH-COPD. METHOD: Patients attending our PHclinic were reviewed for PH-COPD receiving PH-target therapy. Baseline characteristics, death/transplantation until 2014, therapy, NYHA functional class, 6 min walk distance (6MWD) and oxygen saturation (SpO2) at baseline, 3, 6, 12 and 24 months were analysed. RESULTS: Of 48 PH-COPD identified 21 were excluded (insufficient data, comorbidity). 27 patients ( 7 females, 21 smokers, 23 emphysema) with median (quartiles) baseline age $70(60 ; 76)$ years, FEV1 $60(46 ; 78) \%$, FEV1/FVC 57 (51; 64) $\%$, DLCO $42(36 ; 59) \%$, mean pulmonary artery pressure $39(32 ; 44) \mathrm{mmHg}$ under inhaled iloprost (10), subcutaneous prostanoids (2), intravenous prostanoids (3), endothelin receptor antagonists (15) and phosphodiesterase-5-inhibitors (25) were included. Under therapy, NYHA functional class improved from $3.5(3 ; 4)$ to $3(2 ; 4)$ after 3 months and $3(2 ; 3.5)$ after 6 months $(\mathrm{p}=.02$ and .008$)$. The 6MWD improved from $373(236 ; 452)$ to $395(339 ; 472), 414(285 ; 492)$ and $396(308 ; 497) \mathrm{m}$ at 3,6 and 12 months $(\mathrm{p}=.005, .006$ and .011$)$ with unchanged resting-SpO2 but decreased peak-exercise SpO2. During median follow-up of $5.9(2.3 ; 8.4)$ years, 10 died, 2 were transplanted and 2 were lost to follow-up. Transplant-free survival at 1,2,3 years was 92,69,54\% and was similar for GOLD stages 1-4, but worse for patients with mPAP $40 \mathrm{mmHg}(\mathrm{p}=.026), 6 \mathrm{MWD}<370 \mathrm{~m}(\mathrm{p}=0.008)$, resting $\mathrm{SpO} 2<92 \%(\mathrm{p}=$ $0.02)$ and peak-walk SpO2 <87\% $(\mathrm{p}=0.012)$. CONCLUSION: PH-target vasodilator therapy improved NYHA functional class and 6MWD up to one year in highly selected patients with severe PH-COPD. Poor exercise capacity, low SpO2 and high mean pulmonary artery pressure at baseline but not airflow obstruction were associated with unfavourable outcome.
\end{abstract}

DOI: https://doi.org/10.1007/s00408-014-9650-1

Posted at the Zurich Open Repository and Archive, University of Zurich

ZORA URL: https://doi.org/10.5167/uzh-102414

Journal Article

Published Version

Originally published at:

Fossati, Laura; Müller-Mottet, Séverine; Hasler, Elisabeth; Speich, Rudolf; Bloch, Konrad E; Huber, Lars C; Ulrich Somaini, Silvia (2014). Long-term effect of vasodilator therapy in pulmonary hypertension due to COPD: A retrospective analysis. Lung, 192(6):987-995.

DOI: https://doi.org/10.1007/s00408-014-9650-1 


\title{
Long-term Effect of Vasodilator Therapy in Pulmonary Hypertension due to COPD: A Retrospective Analysis
}

\author{
Laura Fossati · Séverine Müller-Mottet • \\ Elisabeth Hasler • Rudolf Speich • Konrad E. Bloch • \\ Lars C. Huber · Silvia Ulrich Somaini
}

Received: 21 July 2014/ Accepted: 22 September 2014/Published online: 28 October 2014

(c) Springer Science+Business Media New York 2014

\begin{abstract}
Purpose Pulmonary hypertension (PH) due to COPD has dismal prognosis. We reviewed the long-term effect of $\mathrm{PH}-$ target therapy in severe PH-COPD.

Method Patients attending our $\mathrm{PH}$-clinic were reviewed for $\mathrm{PH}-\mathrm{COPD}$ receiving $\mathrm{PH}$-target therapy. Baseline characteristics, death/transplantation until 2014, therapy, NYHA functional class, 6 min walk distance (6MWD) and oxygen saturation $\left(\mathrm{SpO}_{2}\right)$ at baseline, 3, 6, 12 and 24 months were analysed.

Results Of 48 PH-COPD identified 21 were excluded (insufficient data, comorbidity). 27 patients ( 7 females, 21 smokers, 23 emphysema) with median (quartiles) baseline age $70(60 ; 76)$ years, FEV1 $60(46 ; 78) \%$, FEV1/FVC 57 $(51 ; 64) \%$, DLCO $42(36 ; 59) \%$, mean pulmonary artery pressure $39(32 ; 44) \mathrm{mmHg}$ under inhaled iloprost (10),
\end{abstract}

\footnotetext{
L. Fossati · S. Müller-Mottet · E. Hasler · R. Speich ·

K. E. Bloch - L. C. Huber · S. Ulrich Somaini $(\bowtie)$

Head of Pulmonary Hypertension Unit, Clinic for Pulmonology,

University Hospital of Zurich, Raemistrasse 100, 8091 Zurich,

Switzerland

e-mail: silvia.ulrich@usz.ch

L. Fossati

e-mail: laurafossati86@gmail.com

S. Müller-Mottet

e-mail: severine.mueller-mottet@usz.ch

E. Hasler

e-mail: elisabeth.hasler@usz.ch

R. Speich

e-mail: rudolf.speich@usz.ch

K. E. Bloch

e-mail: konrad.bloch@usz.ch

L. C. Huber

e-mail: lars.huber@usz.ch
}

subcutaneous prostanoids (2), intravenous prostanoids (3), endothelin receptor antagonists (15) and phosphodiesterase-5-inhibitors (25) were included. Under therapy, NYHA functional class improved from $3.5(3 ; 4)$ to $3(2 ; 4)$ after 3 months and $3(2 ; 3.5)$ after 6 months ( $p=.02$ and .008$)$. The 6MWD improved from $373(236 ; 452)$ to 395 (339; $472), 414(285 ; 492)$ and $396(308 ; 497) \mathrm{m}$ at 3,6 and 12 months $(p=.005, .006$ and .011) with unchanged resting- $\mathrm{SpO}_{2}$ but decreased peak-exercise $\mathrm{SpO}_{2}$. During median follow-up of $5.9(2.3 ; 8.4)$ years, 10 died, 2 were transplanted and 2 were lost to follow-up. Transplant-free survival at 1,2,3 years was 92,69,54\% and was similar for GOLD stages $1-4$, but worse for patients with mPAP $\geq 40 \mathrm{mmHg}(p=.026), 6 \mathrm{MWD}<370 \mathrm{~m}(p=0.008)$, resting $\mathrm{SpO}_{2}<92 \%(p=0.02)$ and peak-walk $\mathrm{SpO}_{2}$ $<87 \%(p=0.012)$.

Conclusion PH-target vasodilator therapy improved NYHA functional class and 6MWD up to one year in highly selected patients with severe PH-COPD. Poor exercise capacity, low $\mathrm{SpO}_{2}$ and high mean pulmonary artery pressure at baseline but not airflow obstruction were associated with unfavourable outcome.

Keywords Pulmonary hypertension - Chronic obstructive pulmonary disease - Vasodilator therapy

$\begin{array}{ll}\text { List of Abbreviations } \\ \text { COPD } & \begin{array}{l}\text { Chronic obstructive pulmonary disease } \\ \text { Diffusion capacity of the lung for carbon } \\ \text { monoxide }\end{array} \\ \text { FEV1 } & \text { Forced expiratory volume in } 1 \mathrm{~s} \\ \text { FVC } & \text { Forced vital capacity } \\ \text { mPAP } & \text { Mean pulmonary artery pressure } \\ \text { NYHA } & \text { New York Heart Association } \\ \text { PH } & \text { Pulmonary hypertension }\end{array}$

List of Abbreviations

COPD Chronic obstructive pulmonary disease

FEV1 Forced expiratory volume in $1 \mathrm{~s}$

FVC Forced vital capacity

mPAP Mean pulmonary artery pressure

$\mathrm{PH} \quad$ Pulmonary hypertension 
PH-COPD Pulmonary hypertension due to COPD

PAWP Pulmonary artery wedge pressure

PVR Pulmonary vascular resistance

QoL Quality of life

RHC Right heart catheter

6MWD 6 min walk distance

$\mathrm{SpO}_{2} \quad$ Peripheral oxygen saturation

WHO World Health Organisation

\section{Introduction}

Pulmonary hypertension (PH) is defined by the World Health Organisation (WHO) as a mean pulmonary artery pressure $(\mathrm{mPAP}) \geq 25 \mathrm{mmHg}$ at rest during right heart catheterization (RHC) and is classified into 5 major groups $[1,2]$. After $\mathrm{PH}$ due to left heart diseases, $\mathrm{PH}$ due to chronic lung diseases is most common and within this, chronic obstructive pulmonary disease (COPD) is the most frequent cause owing to the high prevalence of COPD worldwide [3]. COPD is defined as a slowly progressive systemic disease, characterized by a fixed airflow obstruction by spirometry [4]. COPD has been classified by the global initiative for chronic obstructive lung disease (GOLD) in 4 categories according to the forced expiratory volume in $1 \mathrm{~s}$ (FEV1) [5]. According to the WHO, 210 million people are affected by COPD worldwide and it was estimated that around 3 million people died of COPD, which corresponds to $5 \%$ of all deaths globally [3, 5]. Thus, COPD is a leading cause of morbidity worldwide and will become the fourth cause of mortality in 2030 [3]. The main cause of COPD is certainly cigarette smoking, especially in the western world, but also indoor and outdoor air pollution, occupational dusts and alpha-1-antitrypsin deficiency are important risk factors [3, 4].

Mild and typically exercise-induced $\mathrm{PH}$ is frequently found in COPD with increasing prevalence with more severe airflow limitation and PH in COPD is especially associated with chronic hypoxemia [6-8]. The prevalence of $\mathrm{PH}$ due to COPD (PH-COPD) is not well known, mainly as RHC is not done routinely and the prevalence may vastly vary according to the setting (ambulatory, general practitioners vs. specialist centres with severe cases). Despite PH-COPD usually being mild (mPAP $<30 \mathrm{mmHg}$ ), some patients develop a severe and rapidly progressive $\mathrm{PH}$ ( $\mathrm{mPAP} \geq 35 \mathrm{mmHg}$ ) leading to death or necessitating lung transplantation [8-10]. The latter are sometimes called "out of proportion" cases, although this terminology has never been standardized and is abandoned by some experts [9]. It is important to know, that the severity of airflow obstruction does not correlate with the mPAP and thus, PH might be observed with mild airflow limitation [7, 9]. PH in COPD is a significant risk factor for hospitalization, for acute exacerbation and is associated with a worse survival [11, 12]. Main pathogenetic mechanisms involved in PH-COPD are hypoxic pulmonary vasoconstriction, remodelling of pulmonary vessels, inflammation, pulmonary microthrombosis and the reduction in the number of pulmonary vessel in emphysema $[6,13]$.

Up to now, there is no specific therapy for PH-COPD [9]. According to pathogenesis, smoking cessation, longterm oxygen therapy and treatment of airflow obstruction by inhalation therapy or treatment of right heart failure by diuretics are therapeutic cornerstones [9]. Treatment with vasodilator therapy as used for pulmonary arterial hypertension, namely prostanoids, endothelin receptor antagonists (ERA) and phosphodiesterase-5-inhibitors (PDE5I), is not recommended due to the lack of randomized controlled trials and the fear that they may impair gas exchange due to pulmonary vasodilation and increased ventilation-perfusion mismatch [9, 14]. On the other hand, favourable antiproliferative and vasodilator effects of $\mathrm{PH}$-target therapy (prostanoids, ERA and PDE5I) might be of value in some patients with severe PH-COPD in order to reduce the afterload of the right heart, in analogy to other forms of $\mathrm{PH}$ $[9,15]$. In lack of RCT, the aims of the present study were to identify all patients with $\mathrm{PH}-\mathrm{COPD}$ who received $\mathrm{PH}$ targeted therapy for at least 3 months, to look at changes in exercise performance, quality of life (QoL), functional class, hemodynamic, blood oxygenation, safety and eventfree survival with these therapies.

\section{Methods}

Patients

Datasets of all patients attending our PH-outpatient clinic were reviewed, in this retrospective data analysis, to identify patients with PH-COPD. Patients were included if they had $\mathrm{PH}$ defined as $\mathrm{mPAP} \geq 25 \mathrm{mmHg}$ with a pulmonary artery wedge pressure (PAWP) $\leq 15 \mathrm{mmHg}$ during right heart catheterisation along with a diagnosis of COPD defined as $\mathrm{FEV}_{1} / \mathrm{FVC}<0.7$ and if $\mathrm{PH}$-target therapy had been started and taken for at least 3 months. PH-target therapy was defined as parenteral prostanoids, ERA and PDE5I. Patients were excluded if they had another reason for their PH, namely chronic left heart disease (PAWP $\geq 15 \mathrm{mmHg}$ ), thromboembolic $\mathrm{PH}$, $\mathrm{PH}$ associated with connective tissue diseases, interstitial or other significant parenchymal lung disease at high resolution thoracic CT, other PH classification (HIV, drugs- and toxins) or a combination of these. The outpatient clinic database was searched to identify cases diagnosed with PH from January 2000 to end of December 2013. The study was approved by 
the Cantonal ethical review board Zurich (KEK-20130553).

\section{Data Retrieval, Analysis and Statistics}

All patients' records were thoroughly reviewed and the following characteristics and parameters noted at baseline just before the start of PH-target therapy: age, sex, smoking status and history, pulmonary function test, the presence of emphysema at chest computed tomography, pulmonary hemodynamics by right heart catheterisation and echocardiography, haemoglobin, NT-pro-brain natriuretic peptide (NT-pro-BNP), 6MWD, New York Heart Association (NYHA) functional class and QoL (Minnesota living with heart failure questionnaire;MLHF).

According to the practice at our $\mathrm{PH}$-clinic, patients under PH-target therapies have regular follow-up visits at 3, 6, 12 and 24 months and at least yearly thereafter with assessments of 6MWD, NYHA class, MLHF and NT-proBNP. This close follow-up allowed having complete follow-up (defined as death or lung transplantation).

Descriptive statistics for median (quartiles) were used, and analysis of variance for repeated measures (Friedmantest) and Wilcoxon matched pair tests were used to compare baseline values with values after $3,6,12$ and 24 months of therapy. Event-free survival was calculated by Kaplan-Meier analysis over all PH-COPD patients and stratified by disease severity, namely by GOLD-classes, the medians of mPAP or $\mathrm{SpO}_{2}$ at rest and peak-walk. Cox regression was used to look for the predictive value of baseline valuables or changes with therapy after 3 months. Pearson's correlation between PH and COPD was calculated. A $p<0.05$ was considered significant.

\section{Results}

From 493 PH-datasets, 48 were classified as PH-COPD. 21 had to be excluded due to diagnostic failure, comorbidity or no PH-target therapy (Fig. 1). Characteristics of 27 included patients are shown in Table 1.3/4 of patients were male smokers ( $1 / 5$ persistent) and severely limited (half in NYHA class IV) with a markedly reduced 6MWD. Airflow limitation was comparably mild with a median $\mathrm{FEV}_{1}$ of $60 \%$ and the majority being in Gold stage I or II, emphysema was documented in $92 \%$. Pulmonary hemodynamics were severely compromised [mPAP of 39 (32; 44) $\mathrm{mmHg}$. Most patients had single bronchodilator therapy; inhaled steroids were used in half. $60 \%$ of patients used supplemental oxygen at least during nights, $89 \%$ were anticoagulated. The NT-pro-BNP was elevated [653 $(159 ; 1,194) \mathrm{ng} / \mathrm{l}$, normally $<300 \mathrm{ng} / \mathrm{l}]$. We found no

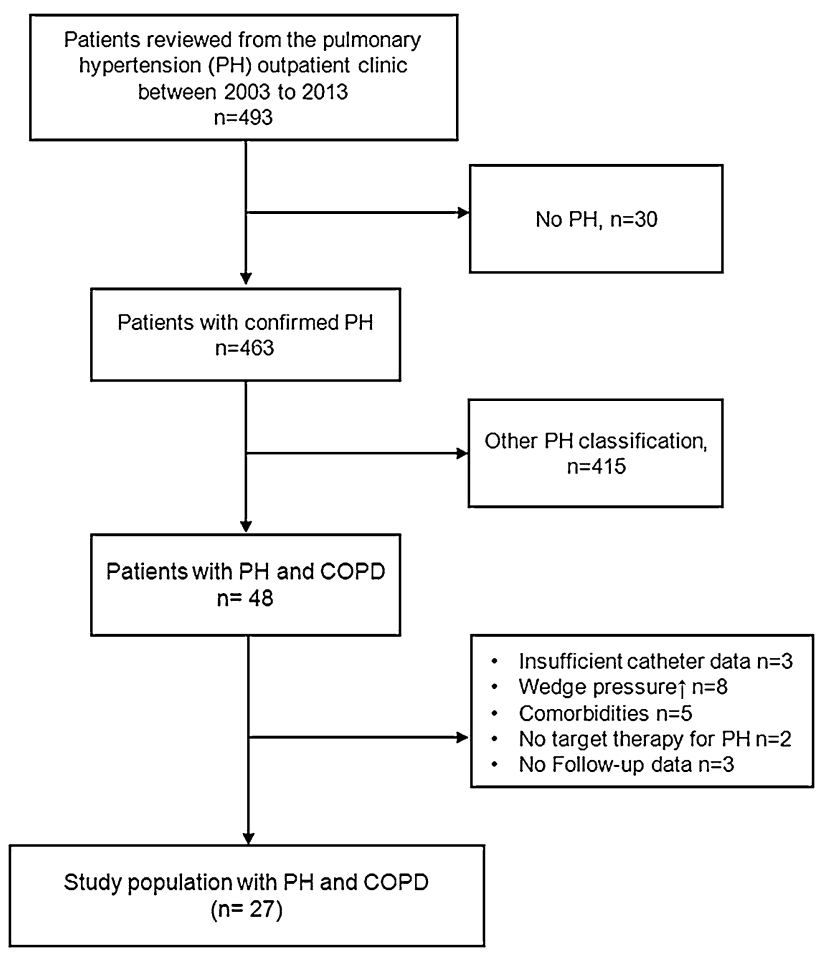

Fig. 1 Patient flow. COPD chronic obstructive pulmonary disease, wedge pressure pulmonary artery occlusion pressure. Target therapy: parenteral prostanoids, endothelin receptor antagonists (ERA) and phosphodiesterase-5 inhibitors (PDE5I)

correlation between COPD severity according to baseline $\mathrm{FEV}_{1}$ and the baseline mPAP or PVR, but both parameters significantly correlated with the baseline $\mathrm{SpO}_{2}$.

Patients' PH-target-therapy initiated at baseline and their maximal therapy during the observational period is shown in Table 2. Most patients were treated with PDE5I, followed by ERA and inhaled prostanoids.

Table 3 shows the course of markers of disease severity under therapy: the NYHA improved significantly from 3.5 $(3 ; 4)$ at baseline to $3(2 ; 4)$ at 3 months and $3(2 ; 3.5)$ at 6 months $(p=.020$ and .008). After 1 and after 2 years instead, the values returned to baseline. Figure 2 visualizes changes in NYHA. The 6MWD test increased significantly from $373 \mathrm{~m}(236 ; 452)$ at baseline to $395 \mathrm{~m}(339 ; 472)$ after three months to $414 \mathrm{~m}(285 ; 492)$ after 6 months and to 396 $\mathrm{m}(308 ; 497)$ at 12 months $(p=.005, .006, .011)$. After 2 years, the median was insignificantly higher compared to baseline $434(277 ; 508)$. Changes of the 6MWD are shown in Fig. 3.

The $\mathrm{SpO}_{2}$ did not change under therapy, whereas the peak-exercise $\mathrm{SpO}_{2}$ decreased to $83(76 ; 88, p=.014)$ after 3 months, $81(76 ; 87, p=.014)$ after 6 months, 82 $(80 ; 88.5, p=.116)$ after 1 year and $83.5(73 ; 89.5$, $p=.039)$ after 2 years (Fig. 4). Heart rate, QoL, NT-pro$\mathrm{BNP}$ and tricuspid pressure gradient did not change. 
Table 1 Baseline characteristics of patients with chronic obstructive pulmonary disease and pulmonary hypertension

\begin{tabular}{|c|c|}
\hline & $\begin{array}{l}\text { Number (\%) median } \\
\text { (IQR1; IQR3) }\end{array}$ \\
\hline Total number of patients & $27(100)$ \\
\hline Females & $7(26)$ \\
\hline Age (years) & $70(60 ; 76)$ \\
\hline BMI $\left(\mathrm{kg} / \mathrm{m}^{2}\right)$ & $26(24 ; 30)$ \\
\hline Current smokers & $5 / 26(19)$ \\
\hline Past smokers & $21 / 26(81)$ \\
\hline Peak years smoked until baseline & $40(5 ; 50)$ \\
\hline Peak years total & $40(5 ; 50)$ \\
\hline NYHA functional class II/III/IV & $3 / 9 / 12(12.5 / 37.5 / 50)$ \\
\hline 6 min walk distance $(\mathrm{m})$ & $373(236 ; 452)$ \\
\hline $\begin{array}{l}\text { Resting peripheral oxygen saturation } \\
(\%)\end{array}$ & $92(86 ; 94)$ \\
\hline $\begin{array}{l}\text { Peak exercise peripheral oxygen } \\
\text { saturation }(\%)\end{array}$ & $87(79 ; 91)$ \\
\hline Resting heart rate $\left(\min ^{-1}\right)$ & $83(76 ; 93)$ \\
\hline Peak exercise heart rate $\left(\min ^{-1}\right)$ & $112(101 ; 123)$ \\
\hline $\begin{array}{l}\text { COPD severity by GOLD stage I/II/III/ } \\
\text { IV }\end{array}$ & $6 / 12 / 6 / 3(22 / 44.5 / 22 / 11.5)$ \\
\hline \multicolumn{2}{|l|}{ Pulmonary function tests ( $\%$ predicted) } \\
\hline $\begin{array}{l}\text { Forced expiratory volume in } 1 \mathrm{~s} \\
\left.\text { (FEV }{ }_{1} \% \text { predicted }\right)\end{array}$ & $60(46 ; 78)$ \\
\hline Forced vital capacity (FVC \% predicted) & $84(63 ; 105)$ \\
\hline $\mathrm{FEV}_{1} / \mathrm{FVC}$ & $57(50.5 ; 64)$ \\
\hline Total lung capacity (\% predicted) & $103(90 ; 116)$ \\
\hline Residual volume (\% predicted) & $127(105 ; 189)$ \\
\hline $\begin{array}{l}\text { Carbon monoxide diffusion capacity (\% } \\
\text { predicted) }\end{array}$ & $42(36 ; 59)$ \\
\hline $\begin{array}{l}\text { Emphysema at thoracic computed } \\
\text { tomography }\end{array}$ & $23 / 25(92)$ \\
\hline \multicolumn{2}{|l|}{ Pulmonary hemodynamics } \\
\hline $\begin{array}{l}\text { Mean pulmonary artery pressure } \\
(\mathrm{mmHg})\end{array}$ & $39(32 ; 44)$ \\
\hline Cardiac index $\left[\left(1 / \mathrm{min} \mathrm{m}^{2}\right)\right]$ & $2.4(2.2 ; 3.1)$ \\
\hline $\begin{array}{l}\text { Pulmonary vascular resistance (dyn s/ } \\
\mathrm{m}^{5} \text { ) }\end{array}$ & $420(357 ; 529)$ \\
\hline Right atrial pressure (mmHg) & $7(5 ; 9)$ \\
\hline $\begin{array}{l}\text { Pulmonary artery occlusion pressure } \\
(\mathrm{mmHg})\end{array}$ & $11(9 ; 12)$ \\
\hline $\begin{array}{l}\text { Tricuspid pressure gradient by } \\
\text { echocardiography }(\mathrm{mmHg})\end{array}$ & $57.5(45.75 ; 69.25)$ \\
\hline Haemoglobin (g/l) & $15(14 ; 16)$ \\
\hline NT-pro-BNP (ng/l) & $653(159 ; 1,194)$ \\
\hline \multicolumn{2}{|l|}{ COPD target therapies } \\
\hline $\begin{array}{l}\text { Inhaled bronchodilators (long acting } \\
\text { beta agonist) }\end{array}$ & $17 / 27(63)$ \\
\hline $\begin{array}{l}\text { Inhaled bronchodilators (long acting } \\
\text { muscarinic antagonist) }\end{array}$ & $11 / 25(44)$ \\
\hline Inhaled corticosteroids & $15 / 27(56)$ \\
\hline Oral anticoagulation & $24 / 27(89)$ \\
\hline
\end{tabular}

Table 1 continued

Number (\%) median (IQR1; IQR3)

Supplemental oxygen $16 / 27(60)$

$B M I$ body mass index, NYHA new york heart association, $C O P D$ chronic obstructive pulmonary disease, GOLD global initiative for chronic obstructive pulmonary disease, NT-pro-BNp $N$-terminal pro b-type natriuretic peptide

Table 2 Pulmonary hypertension- target therapies started at baseline and maximal therapy

\begin{tabular}{lc}
\hline & Number (\%) \\
\hline PH-target therapies started at baseline & \\
Prostanoid inhaled & $5 / 27(18.5)$ \\
ERA (endothelin receptor antagonist) & $8 / 27(30)$ \\
PDE5I (phosphodiesterase type 5 inhibitor) & $14 / 27(52)$ \\
Maximal PH-target therapies over whole period & \\
Prostanoid inhaled & $10 / 27(37)$ \\
Prostanoid subcutaneous & $2 / 27(7.5)$ \\
Prostanoid intravenous & $3 / 27(11.5)$ \\
ERA (endothelin receptor antagonist) & $15 / 27(55.5)$ \\
PDE5I (phosphodiesterase type 5 inhibitor) & $25 / 27(93)$ \\
\hline
\end{tabular}

Two patients stopped therapy with ERA. 1 pre-treated with sildenafil after 1 month in lack of efficacy and worsening leg oedema, 1 was switched to PDE-5 inhibitor after 3 months in lack of efficacy. The later was thereafter well supported until now (4 years). Three patients stopped therapy with PDI-5 inhibitors after a mean time of 1.6 (1-3) months due to lacking efficacy. All had been pretreated (2 with ERA, 1 with inhaled iloprost).

We found a positive correlation between the MPAP and PVR at baseline and the change in the 6MWD after 3 months $(p=.01, R=.514$ and $p=.005, R=.563)$. The changes in 6MWD over time did not correlate with other baseline parameters.

During the median follow-up of $5.9(2.3 ; 8.4)$ years, 10 patients died [after $3.1(2.3 ; 4.3)$ years], 2 patients were transplanted [after $2.7(1.7 ; 3.6)$ years], and two were lost to follow-up [after $3.3(2.2 ; 4.4)$ years]. Kaplan-Meier survival analysis shows that patients with an mPAP $\geq 40 \mathrm{mmHg}$ (14 patients) had worse transplant-free survival compared to patients with lower mPAP $(p=.026$, Fig. 5). The transplant-free survival of patients with a baseline 6MWD $<370 \mathrm{~m}$ (14 patients) was significantly worse compared to patients with better 6MWD $(p=.026$, Fig. 6). Additionally, patients with a resting $\mathrm{SpO}_{2}<92 \%$ $\left(p=.02,13\right.$ patients) and with a peak-exercise $\mathrm{SpO}_{2}$ 


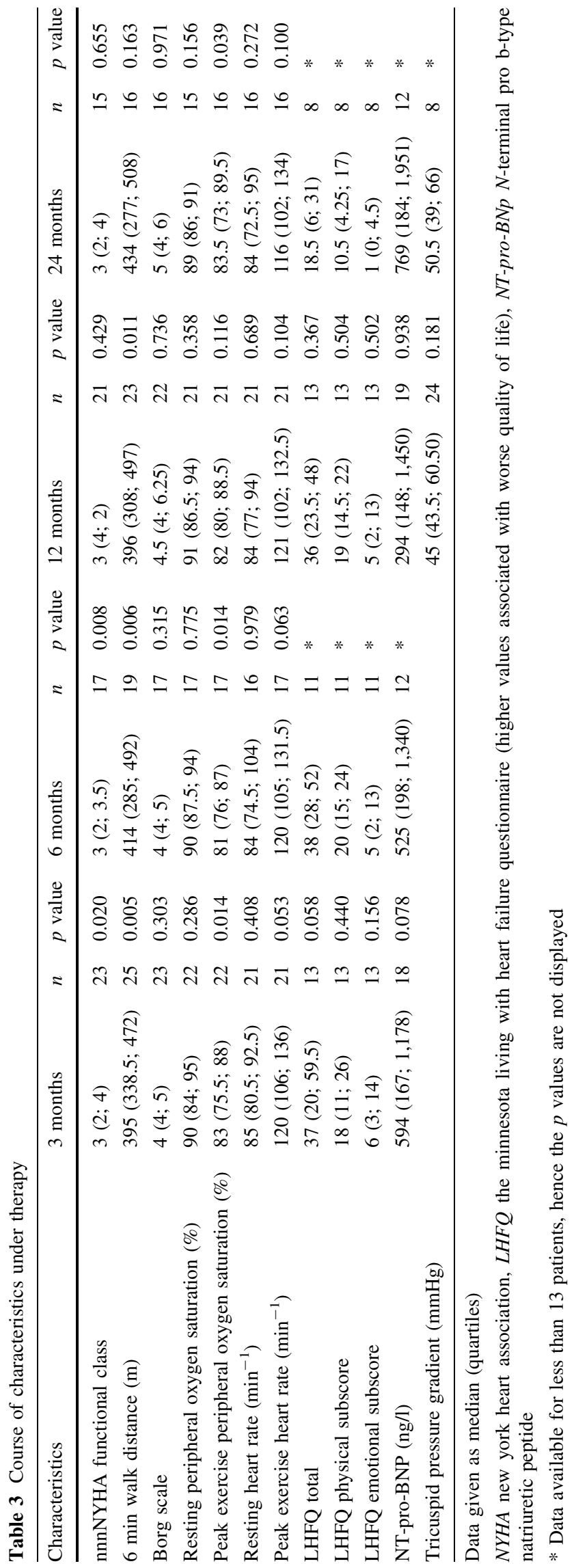

$<87 \%(p=.012,11$ patients $)$ had worse transplant-free survival. Transplant-free survival was not different according to GOLD stages or therapies. Cox regression revealed that the 6MWD was the only predictor of transplant-free survival $(\beta=.006, p=.039)$ whereas age, FEV1 $(\beta=.012, p=.51)$, mPAP $(\beta=.078, p=.08)$, PVR $(\beta=.003, \quad p=.07)$ and $\mathrm{SpO}_{2} \quad(\beta=-.128$, $p=.126)$ were not.

\section{Discussion}

In this retrospective study in highly selected patients with severe PH-COPD treated at a specialized PH-center, we found that pulmonary selective vasodilator PH-target therapy improved functional class and 6MWD, with sustained improvements over 1 year. Event-free survival was better with better hemodynamics, exercise performance and blood oxygenation, but was not influenced by airflow limitation.

One of the complications of COPD is that patients may develop PH. However, the epidemiology of PH-COPD is incompletely known and vastly varies according to the setting (ambulatory patients, regional hospitals, intensive care units, tertiary care centres with specialized units) $[6$, 9]. In advanced COPD before lung volume reduction surgery or transplantation, a $\mathrm{PH}$ prevalence of $>50 \%$ was found $[10,16]$. The prevalence of PH-COPD differed by GOLD stages with 5, 27 and $53 \%$ for stages II, III and IV [17]. PH in COPD is prognostically important; however, $\mathrm{RCT}$ for PH-therapy for these patients are lacking [6, 9, 12]. In the present retrospective analysis of PH-target therapy in a highly selected collective of patients, we found that functional class and the 6MWD improved for up to 2 years. The resting $\mathrm{SpO}_{2}$ was unaffected by therapy whereas peak exercise $\mathrm{SpO}_{2}$ decreased. These findings are in line with a RCT in 37 patients with PH-COPD, who were treated with sildenafil, which found an improved exercise performance and a reduction of mPAP in patients with severe PH-COPD under PDE5I-therapy [18]. However, other studies reached contradictive results. Lange et al. recently described a better survival in a retrospective cohort of treated PH-COPD, but no effect of therapy on the exercise capacity [19]. Blanco et al. investigated the effect of sildenafil given for 3 months in addition to training to COPD patients with mild $\mathrm{PH}$ at echocardiography [20]. The improvements under training were similar in the sildenafil- and placebo-treated groups with similar changes in oxygenation and quality of life [20]. Others have shown that the increase of mPAP during exercise was attenuated by sildenafil; however, the exercise capacity did not improve [21]. It is important to note that the latter study analysed data of 18 COPD patients among whom just 5 had 
Fig. 2 New York Heart Association functional class (NYHA): course under therapy. Data given as percent. $N=$ number of patients assessed
Fig. 3 Evolution of the 6 min walk distance in metres under therapy. Data given as median (quartiles). $* p<.05$.

$N=$ number of patients assessed
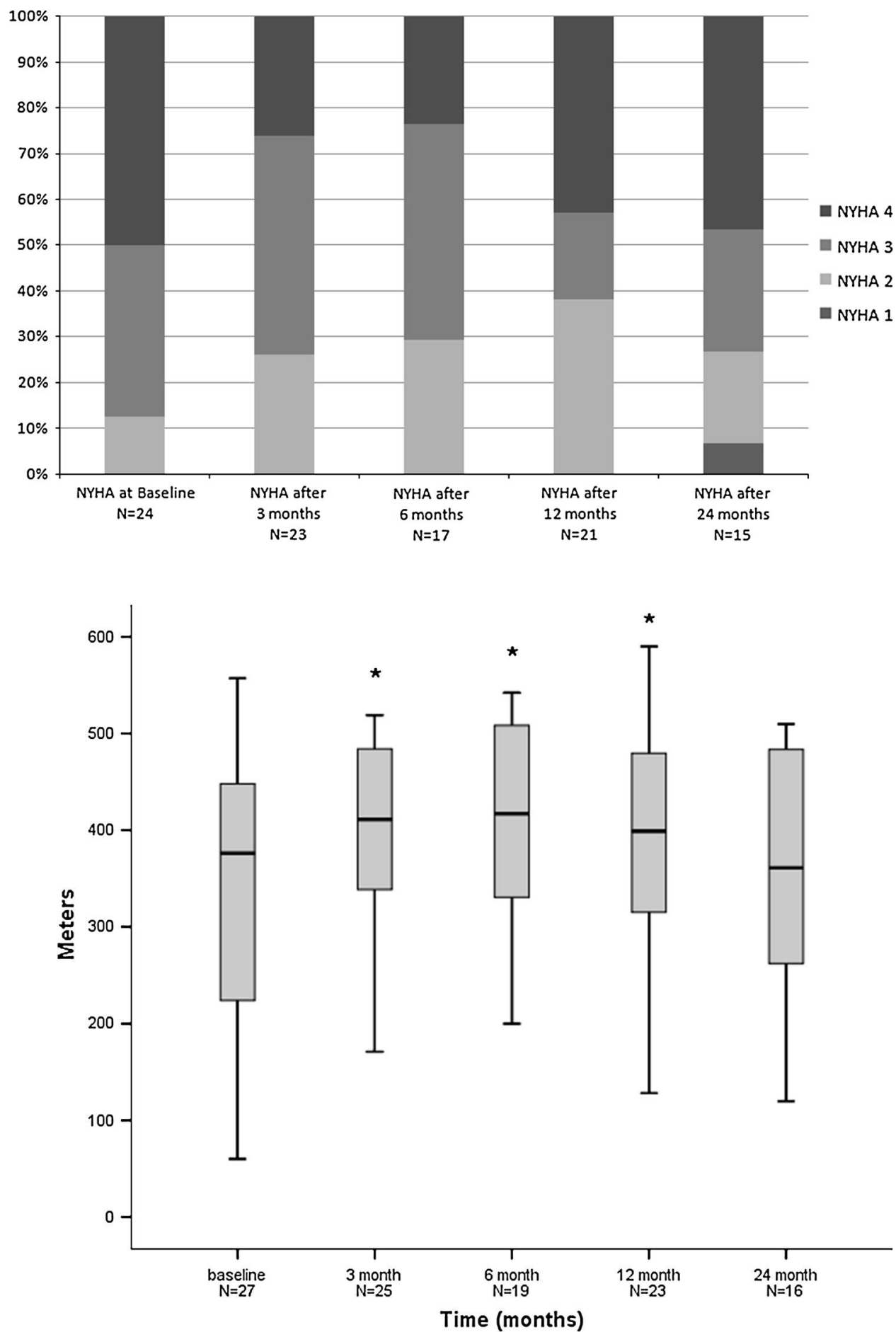

PH. Others showed that exercise capacity and stroke volume did not improve under sildenafil in a collective of COPD patients in whom not all had $\mathrm{PH}$ [22]. In another COPD-collective without resting $\mathrm{PH}$, exercise capacity was not increased by sildenafil but the gas exchange and QoL were impaired under therapy along with more adverse events [23]. There are few studies analysing the effect of bosentan in patients with COPD, and the results seem to be controversial. One study showed a positive effect of bosentan in patients with PH-COPD [24], the therapy seemed to stop the progressive increase of mPAP and PVR. Another study found no improvement in exercise capacity, but deterioration of hypoxemia and functional status [25]. Of note, this study included patient with COPD without or only mild $\mathrm{PH}$ as assessed by echocardiography and not RHC [25]. Thus, the heterogeneity of response to PH-target 
Fig. 4 Peripheral oxygen saturation: comparison between rest and peak exercise oxygen saturation at baseline and under therapy after $3,6,12$,

24 months. $95 \%$ confidence intervals, data given as median, $N=$ number of patients assessed

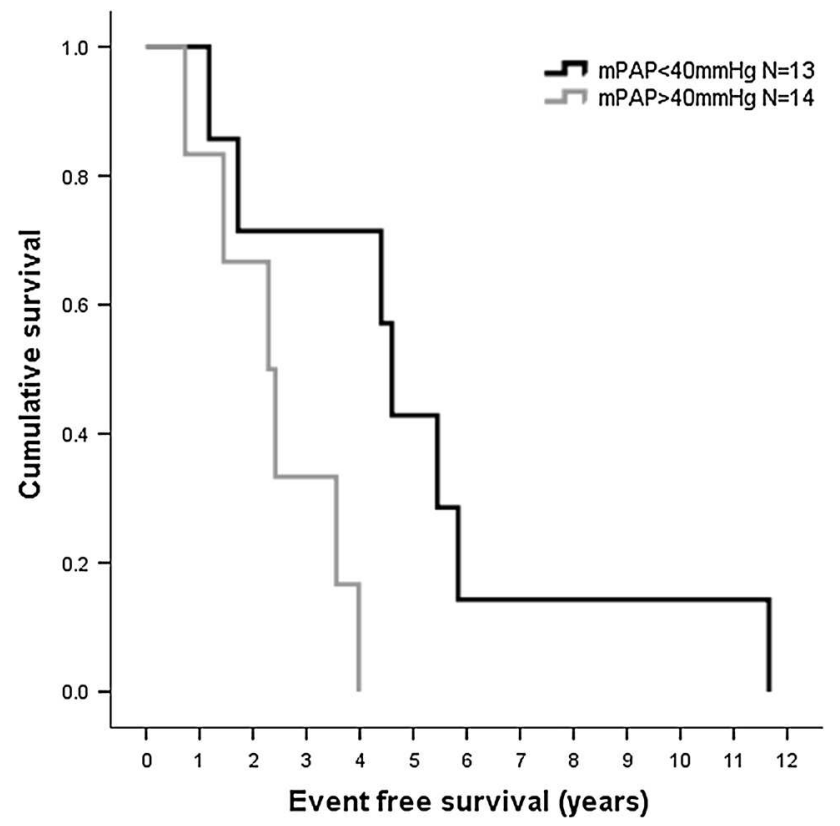

Fig. 5 Kaplan-Meier survival plots are shown for patients with mean pulmonary artery pressure of $>40$ and $<40 \mathrm{mmHg}$. $N=$ number of patients assessed

therapy might be due to patients' selection and the presence of relevant $\mathrm{PH}$.

We analysed the development of $\mathrm{SpO}_{2}$ during therapy at rest and at peak exercise in the 6MWD test. We found that resting $\mathrm{SpO}_{2}$ did not change under $\mathrm{PH}$-target therapy, whereas peak exercise desaturation increased along with an

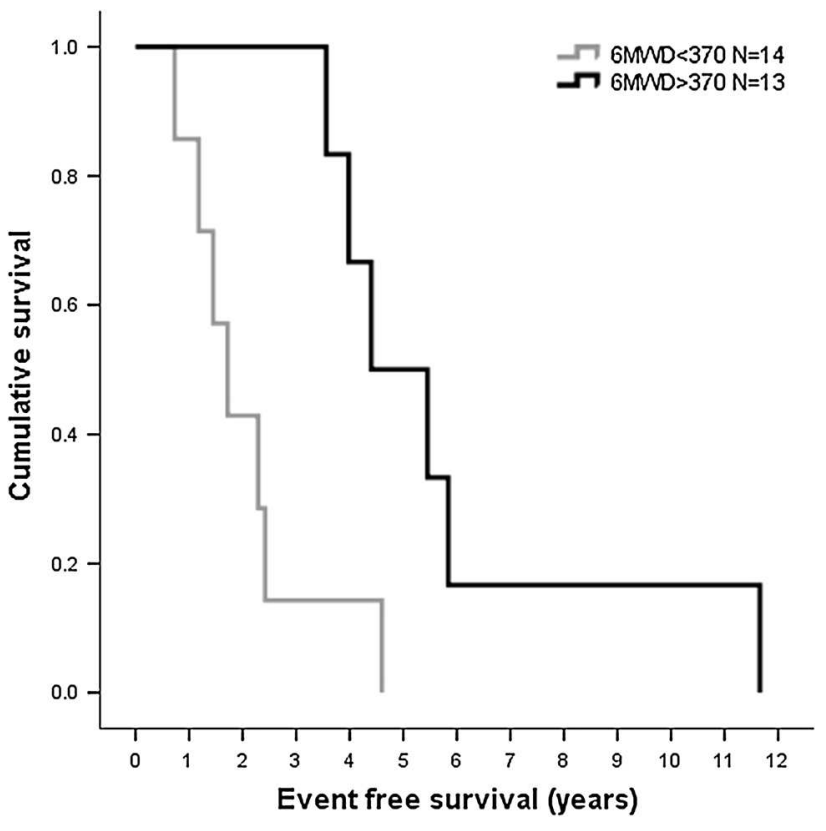

Fig. 6 Kaplan-Meier survival plots are shown for patients with a 6 min walk distance $<370$ and $>370 \mathrm{~m}$. $N=$ number of patients assessed

increased exercise capacity. Thus, our results may support an increased ventilation-perfusion mismatch at peak exercise however along with an increased exercise capacity potentially due to a decreased RV afterload. A study investigating the acute effect of sildenafil during exercise in $\mathrm{PH}-\mathrm{COPD}$ showed a reduced $\mathrm{mPAP}$ and $\mathrm{PaO}_{2}$ at rest 
under therapy; however, only the mPAP further decreased with exercise but not the $\mathrm{PaO}_{2}$ [26]. In regard to prostanoids contradictory effects on ventilation-perfusion mismatch were reported. In a study investigating 26 patients with exacerbated COPD, prostaglandin E1 given intravenously (IV) decreases mPAP without worsening blood gases [27]. On the other hand, in a placebo-controlled trial in 16 COPD patients with acute respiratory failure, PVR reduction under IV-prostanoids was only temporary and accompanied by a significant fall in $\mathrm{SpO}_{2}$ [28]. Similar unfavourable effects of IV-prostanoids were found by others [29, 30]. In our cohort, only 3 patients received IVprostanoid as rescue therapy. The first of these 3 patients was transplanted after 4.6 year, the second died after 2.6 years and the third survives for 5 years now. Five patients in our cohort were treated with inhaled iloprost. Inhaled iloprost potentially acts preferentially in wellventilated regions of the lung, thereby reducing $\mathrm{PH}$ with less effect ventilation-perfusion mismatch [31]. Others did not find an improvement of exercise capacity and showed that the oxygenation at rest deteriorated [32]. Since results of PH-target therapies in PH-COPD are so controversial, there is an obviously need for further and more in depth studies in collectives of COPD patients with relevant $\mathrm{PH}$ with exact characterization of hemodynamics by right heart catheterisation, gas exchange and airflow limitation.

In our study, we found a marginally insignificant improvement in QoL $(p=.058)$ after 3 months of treatment. Unfortunately, in our retrospective analysis not all patients did have regular QoL assessments. However, this important patient-centered outcome should be assessed in future, well-performed trials.

PH-COPD is associated with worse survival [6, 11, 12]. This could be confirmed in our study, as patients with a mPAP $>40 \mathrm{mmHg}$ had a worse event-free survival. Similarly, patients with $6 \mathrm{MWD}<370 \mathrm{~m}$ and low resting or peak-exercise $\mathrm{SpO}_{2}$, but not patients with worse GOLD stages had worse event-free survival. This may indicate that pulmonary hemodynamics and impaired blood oxygenation are prognostically more important than mere airflow limitation in this COPD-collective with marked $\mathrm{PH}$ and thus strengthen the need for effective therapies to improve $\mathrm{PH}$ without affecting gas exchange in this potentially vast collective. Of note, most of these patients had a relatively good GOLD stage, this might be the reason why we did not found a prognostic relevance of FEV1 in this collective.

The only parameter which predicted the patients' eventfree survival in cox regression was the 6MWD at baseline, but not the change in 6MWD or other parameters. Other studies have emphasized the importance of exercise capacity as outcome parameter in COPD, e.g. Pinto-Plata et al. showed that the 6WMD in patient with severe COPD is a better predictor of mortality than the degree of obstruction, BMI and associated comorbidities [33, 34].

Our study has the following limitations: As this is a retrospective data analysis, not all patients had regular follow-up available at each time-point and thus, we do not know whether the results would have been different if all patients would have had every outcome. The retrospective design is also limited by potential selection and referral bias: Our PH-COPD cohort was retrieved from a specialist PH-outpatient clinic. This might explain why the mPAP was relatively high and thus the results are not transferable to COPD patients with mild or only exercise-induced $\mathrm{PH}$. In addition, our study was too small to look at the different PH-target therapy classes separately. Accordingly, we are not able to draw inference on these aspects and it may well be that one therapy outreaches another. Despite these drawbacks, in lack of RCTs in the field, we believe that it is important to collect as much information as possible on the effect of PH-target therapy in selected PH-COPD collectives until data from well-designed RCTs get available.

\section{Conclusions}

In this selected cohort of patients with severe PH-COPD, PH-target vasodilator therapy did improve NYHA functional class and 6MWD without worsening resting $\mathrm{SpO}_{2}$ for up to 1 year. Poor exercise capacity, $\mathrm{SpO}_{2}$ and high mPAP at baseline were associated with shortened transplant-free survival but not worse airflow obstruction. The baseline 6MWD was the only independent predictor of survival.

Acknowledgments SU and KEB received grants from the Swiss National Science Foundation and the Zurich Lung League. Both Funding sources did not have any influence on the design, data collection, analysis or interpretation of data or writing of the manuscript.

Conflict of interest LF and KEB have no competing interest. SMM, $\mathrm{EH}, \mathrm{RS}, \mathrm{LCH}$ and $\mathrm{SU}$ have received reimbursements for travelling to congresses/speaker fees from Actelion, Switzerland and/or Bayer, Germany.

\section{References}

1. Simonneau G, Gatzoulis MA, Adatia I, Celermajer D, Denton C, Ghofrani A, Gomez Sanchez MA, Krishna Kumar R, Landzberg M, Machado RF, Olschewski H, Robbins IM, Souza R (2013) Updated clinical classification of pulmonary hypertension. J Am Coll Cardiol 62(25 Suppl):D34-D41

2. Galie N, Hoeper MM, Humbert M, Torbicki A, Vachiery JL, Barbera JA, Beghetti M, Corris P, Gaine S, Gibbs JS, GomezSanchez MA, Jondeau G, Klepetko W, Opitz C, Peacock A, Rubin L, Zellweger M, Simonneau G (2009) Guidelines for the diagnosis and treatment of pulmonary hypertension. The task 
force for the diagnosis and treatment of pulmonary hypertension of the European Society of Cardiology (ESC) and the European Respiratory Society (ERS), endorsed by the International Society of Heart and Lung Transplantation (ISHLT). Eur Respir J 34:1219-1263

3. World Health Organisation (2014) Burden of COPD. World Health Organisation, Geneva

4. BTS (1997) BTS guidelines for the management of chronic obstructive pulmonary disease. The COPD Guidelines Group of the Standards of Care Committee of the BTS. Thorax 52(Suppl 5):S1-28

5. Asia-Pacific COPD (2005) Global Initiative for Chronic Obstructive Lung Disease strategy for the diagnosis, management and prevention of chronic obstructive pulmonary disease: an Asia-Pacific perspective. Respirology 10(1):9-17

6. Chaouat A, Naeije R, Weitzenblum E (2008) Pulmonary hypertension in COPD. Eur Respir J 32(5):1371-1385

7. Ulrich $S$, Hersberger M, Fischler M, Nussbaumer-Ochsner $Y$, Treder U, Russi EW, Speich R (2010) Genetic polymorphisms of the serotonin transporter, but not the $2 \mathrm{a}$ receptor or nitric oxide synthetase, are associated with pulmonary hypertension in chronic obstructive pulmonary disease. Respiration 79(4):288-295

8. Weitzenblum E, Chaouat A, Canuet M, Kessler R (2009) Pulmonary hypertension in chronic obstructive pulmonary disease and interstitial lung diseases. Semin Respir Crit Care Med 30(4):458-470

9. Seeger W, Adir Y, Barbera JA, Champion H, Coghlan JG, Cottin V, De Marco T, Galie N, Ghio S, Gibbs S, Martinez FJ, Semigran MJ, Simonneau G, Wells AU, Vachiery JL (2013) Pulmonary hypertension in chronic lung diseases. J Am Coll Cardiol 62(25 Suppl):D109-D116

10. Thabut G, Dauriat G, Stern JB, Logeart D, Levy A, MarrashChahla R, Mal H (2005) Pulmonary hemodynamics in advanced COPD candidates for lung volume reduction surgery or lung transplantation. Chest 127(5):1531-1536

11. Kessler R, Faller M, Weitzenblum E, Chaouat A, Aykut A, Ducolone A, Ehrhart M, Oswald-Mammosser M (2001) "Natural history" of pulmonary hypertension in a series of 131 patients with chronic obstructive lung disease. Am J Respir Crit Care Med 164(2):219-224

12. Oswald-Mammosser M, Weitzenblum E, Quoix E, Moser G, Chaouat A, Charpentier C, Kessler R (1995) Prognostic factors in COPD patients receiving long-term oxygen therapy. Importance of pulmonary artery pressure. Chest 107(5):1193-1198

13. Chaouat A, Bugnet AS, Kadaoui N, Schott R, Enache I, Ducolone A, Ehrhart M, Kessler R, Weitzenblum E (2005) Severe pulmonary hypertension and chronic obstructive pulmonary disease. Am J Respir Crit Care Med 172(2):189-194

14. Barbera JA, Roger N, Roca J, Rovira I, Higenbottam TW, Rodriguez-Roisin R (1996) Worsening of pulmonary gas exchange with nitric oxide inhalation in chronic obstructive pulmonary disease. Lancet 347(8999):436-440

15. Galie N, Corris PA, Frost A, Girgis RE, Granton J, Jing ZC, Klepetko W, McGoon MD, McLaughlin VV, Preston IR, Rubin LJ, Sandoval J, Seeger W, Keogh A (2013) Updated treatment algorithm of pulmonary arterial hypertension. J Am Coll Cardiol 62(25 Suppl):D60-D72

16. Andersen KH, Iversen M, Kjaergaard J, Mortensen J, NielsenKudsk JE, Bendstrup E, Videbaek R, Carlsen J (2012) Prevalence, predictors, and survival in pulmonary hypertension related to end-stage chronic obstructive pulmonary disease. J Heart Lung Transplant 31(4):373-380

17. Hilde JM, Skjorten I, Hansteen V, Melsom MN, Hisdal J, Humerfelt S, Steine K (2013) Haemodynamic responses to exercise in patients with COPD. Eur Respir J 41(5):1031-1041
18. Rao RS, Singh S, Sharma BB, Agarwal VV, Singh V (2011) Sildenafil improves six-minute walk distance in chronic obstructive pulmonary disease: a randomised, double-blind, placebo-controlled trial. Indian J Chest Dis Allied Sci 53(2):81-85

19. Lange TJ, Baron M, Seiler I, Arzt M, Pfeifer M (2014) Outcome of patients with severe $\mathrm{PH}$ due to lung disease with and without targeted therapy. Cardiovasc Ther 32(5):202-208

20. Blanco I, Santos S, Gea J, Guell R, Torres F, Gimeno-Santos E, Rodriguez DA, Vilaro J, Gomez B, Roca J, Barbera JA (2013) Sildenafil to improve respiratory rehabilitation outcomes in COPD: a controlled trial. Eur Respir J 42(4):982-992

21. Holverda S, Bogaard HJ, Groepenhoff H, Postmus PE, Boonstra A, Vonk-Noordegraaf A (2008) Cardiopulmonary exercise test characteristics in patients with chronic obstructive pulmonary disease and associated pulmonary hypertension. Respiration 76(2):160-167

22. Rietema H, Holverda S, Bogaard HJ, Marcus JT, Smit HJ, Westerhof N, Postmus PE, Boonstra A, Vonk-Noordegraaf A (2008) Sildenafil treatment in COPD does not affect stroke volume or exercise capacity. Eur Respir J 31(4):759-764

23. Lederer DJ, Bartels MN, Schluger NW, Brogan F, Jellen P, Thomashow BM, Kawut SM (2012) Sildenafil for chronic obstructive pulmonary disease: a randomized crossover trial. COPD 9(3):268-275

24. Valerio G, Bracciale P, Grazia D'Agostino A (2009) Effect of bosentan upon pulmonary hypertension in chronic obstructive pulmonary disease. Ther Adv Respir Dis 3(1):15-21

25. Stolz D, Rasch H, Linka A, Di Valentino M, Meyer A, Brutsche M, Tamm M (2008) A randomised, controlled trial of bosentan in severe COPD. Eur Respir J 32(3):619-628

26. Blanco I, Gimeno E, Munoz PA, Pizarro S, Gistau C, RodriguezRoisin R, Roca J, Barbera JA (2010) Hemodynamic and gas exchange effects of sildenafil in patients with chronic obstructive pulmonary disease and pulmonary hypertension. Am J Respir Crit Care Med 181(3):270-278

27. Naeije R, Melot C, Mols P, Hallemans R (1982) Reduction in pulmonary hypertension by prostaglandin E1 in decompensated chronic obstructive pulmonary disease. Am Rev Respir Dis 125(1):1-5

28. Archer SL, Mike D, Crow J, Long W, Weir EK (1996) A placebo-controlled trial of prostacyclin in acute respiratory failure in COPD. Chest 109(3):750-755

29. Jones K, Higenbottam T, Wallwork J (1989) Pulmonary vasodilation with prostacyclin in primary and secondary pulmonary hypertension. Chest 96(4):784-789

30. Dujic Z, Eterovic D, Tocilj J, Kusic Z, Capkun V (1993) About mechanisms of prostaglandin E1 induced deterioration of pulmonary gas exchange in COPD patients. Clin Physiol 13(5):497-506

31. Dernaika TA, Beavin M, Kinasewitz GT (2010) Iloprost improves gas exchange and exercise tolerance in patients with pulmonary hypertension and chronic obstructive pulmonary disease. Respiration 79(5):377-382

32. Boeck L, Tamm M, Grendelmeier P, Stolz D (2012) Acute effects of aerosolized iloprost in COPD related pulmonary hypertension a randomized controlled crossover trial. PLoS ONE 7(12):e52248

33. Pinto-Plata VM, Cote C, Cabral H, Taylor J, Celli BR (2004) The 6-min walk distance: change over time and value as a predictor of survival in severe COPD. Eur Respir J 23(1):28-33

34. Celli BR, Cote CG, Marin JM, Casanova C, Montes de Oca M, Mendez RA, Pinto Plata V, Cabral HJ (2004) The body-mass index, airflow obstruction, dyspnea, and exercise capacity index in chronic obstructive pulmonary disease. $\mathrm{N}$ Engl $\mathrm{J}$ Med 350(10):1005-1012 